\title{
DETERMINATION OF HORIZONTAL GEODETIC CONTROL NETWORKS FOR ENGINEERING OBJECTS USING OPTOELECTRONIC TECHNIQUES
}

\author{
Kazimierz Ćmielewski ${ }^{1}$, Janusz Kuchmister ${ }^{1}$, Piotr Gołuch ${ }^{1}$, \\ Izabela Wilczyńska ${ }^{1}$, Krzysztof Kowalski ${ }^{2}$ \\ 1) Institute of Geodesy and Geoinformatics, \\ Wroclaw University of Environmental and Life Sciences \\ 2) Regional Water Management Board in Wroclaw
}

\begin{abstract}
The correctness of the geodetic service of an engineering object not seldom requires designing, alignment or renewing of geodetic situational control points. Building robots often cause that fixed situational control points are partly or completely inaccessible. For setting the position of these control points, there is worked out the methodology using the optoelectronic method. The prepared set of tools realizes the method's assumptions and enables to determine the sides and control points based on the set of laser planes. In this article there is presented the innovative set of geodetic equipment for fixing horizontal control points. The presented set has been experimentally tested under laboratory conditions taking its functionality, operation range and applied accuracy into account. The measurement accuracy of the set of tools, resulting from identification of the energetic centres of laser planes' edges, visualizing the sides of geodetic control networks, is within the range of $\pm 0.02 \mathrm{~mm}- \pm 0.05 \mathrm{~mm}$. There were also discussed exemplary versions of shapes and structures of horizontal geodetic control networks (regular and irregular), which are possible to be fixed with the use of the constructed set of tools.
\end{abstract}

Keywords: engineering geodesy, geodesy in industry, laser planes' edges network, CCD camera

\section{Introduction}

The main aim of geodetic surveys, realized during assembly and modification of different type of devices and mechanic machines on engineering objects, is to set them in vertical position. 
The geodetic setting activities come down to location in the space of the selected points, lines and planes that represent parts of machines or devices in accordance with the project. For small machines there are used workshop methods, which enable to gain high measurement accuracy within relatively small observation space (Ćmielewski, 2007; Matsui and Zhang, 2002).

During assembly of machines and mechanic devices, characterized by large sizes, setting activities as well as activities associated with the control of geometric conditions of the exploited machines, may be realized only with the use of geodetic methods (Batusov et al, 2009; Kuchmister et al, 2012). It comes out of the use of horizontal and vertical geodetic control networks. They compose the reference system that is the basis for any observations. Concerning machine building, the setting out and control surveys are carried out based on proper designed and fixed geodetic control networks, which are called the assembly bases (Kavanagh, 2010; Schofield and Breach, 2007).

The size and shape of horizontal geodetic control networks are strictly connected with the operated machine or the mechanical device (with strict connection to the parameters that characterize the accuracy of geodetic control network with assembly tolerances, set up for the appropriate type of device or machine). The horizontal geodetic control networks should be characterized by the well-matched accuracy parameters, ensuring the attainment of the final measurement effect, which is proper with project requirement (Ágfalvi et al, 2006; Mora, 1998; Pelzer, 1988; Schweitzer et al, 2012).

There are the following types of horizontal assembly bases:

1) Flat assembly bases:

a) elongated bases,

b) surface bases,

c) circular bases,

d) radial- annular and radial bases,

e) optical bases,

2) Assembly spatial bases.

\section{Ad. 1. Flat assembly bases:}

Elongated bases are rectilinear (single or multiple).

They are established parallel to the main axis of the mounted device and are located in a vertical plane, crossing this axis or in a plane, moved a fixed distance from the main axis. They are used for geodetic surveys during building of shipping motors, turbogenerators, machine slides, transmission shafts etc.

Surface bases are dedicated for machines and superficial expanded devices. They are found as geodetic control networks of a shape typical for regular geometric figures (square and rectangular bases), which are used to measure angles and lengths.

Concerning devices that take up larger surfaces there are used nets containing larger number of squares and rectangles. Surface bases might also include traverse networks of any shapes. High flexibility of these networks enables to adjust them to a shape of the operated device.

Elongated bases are used in geodetic works that are led for objects and devices of a circular section or close to this. 
Setting up of these network points' location, assuming that the central point is inaccessible, might be done based on a length measurement of the sides and the angles in the closed polygon.

Radial-annular and radial bases are created for the needs of an operation of unique machines such as f.eg. synchrotrons. Control points are located on an annulus (circumference) as well as in a radius of the basis.

Optical bases may be in a form of a single line, several parallel and perpendicular lines and square or rectangular frame. Creating such bases is based on the use of many mirrors and theodolites that perform functions of autocollimators (Mora, 1998).

Ad. 2. The assembly spatial bases are used during setting up of devices that are expanded in vertical directions. Their task is to secure the right assembly of each part of a device on the determined working levels according to the vertical line. Such geodetic control networks give a chance to do works on different levels at the same time. Spatial network may create any points, fixed on different levels in a way that ensure their link to geometric elements. Mutual connection of points means that in a network there are measured lengths, horizontal and vertical angles in a simple and accurate way. There are often found here regular square or rectangular networks.

To measure geometric quantities at distances of $0.0 \div 40.0 \mathrm{~m}$, there might be used laser trackers (f.eg. LTD800 Leica company), which are three-coordinated measurement instruments. The head of a tracker that emits an infrared laser beam in the direction of the viewfinder, which is a small reflector.

These are complicated devices and because of the type of the emitted laser beam they do not allow to visualize the route of the sides of designed geodetic control networks. The individual visualization of the sides of geodetic control networks is necessary for proper observation site planning (Leica, 2012).

The common accessibility of optoelectronic elements (solid-state lasers, CCD cameras), their small sizes and invariability of the parameters for longer periods of their use, allow for their application in devices that help during survey works (Ćmielewski, 2007; Herty and Albert, 2002; Kuchmister et al, 2012).

The authors created optoelectronic set of tools that visualize the route of the geodetic assembly control network's sides, especially on engineering and industrial objects can be identified in this test.

\section{Project of the set of devices for prolonging or renewing of the setting out horizontal geodetic control networks}

In figure 1 there is presented the laser transmitter, created by the authors, that allows for visualization of the geodetic control network's sides while prolonging and renewing of geodetic control network, whose points have been destroyed or are partially inaccessible.

The next essential element of the set is the transmitter with CCD camera, which is used for setting up of the in space situated planes' position and marking of control points. The design guidelines of the transmitter are shown in figures 2 and 3. 


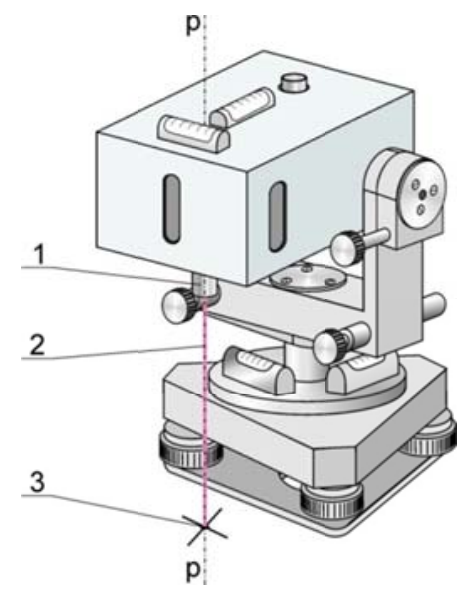

Fig. 1. Project of laser transmitter (which emits three mutually orthogonal planes) with laser plummet. Symbols: 1 - laser diode, 2 - laser plummet, 3 - geodetic point, $p p$ - edge of the intersection of the perpendicular laser planes (axis of the laser plummet).

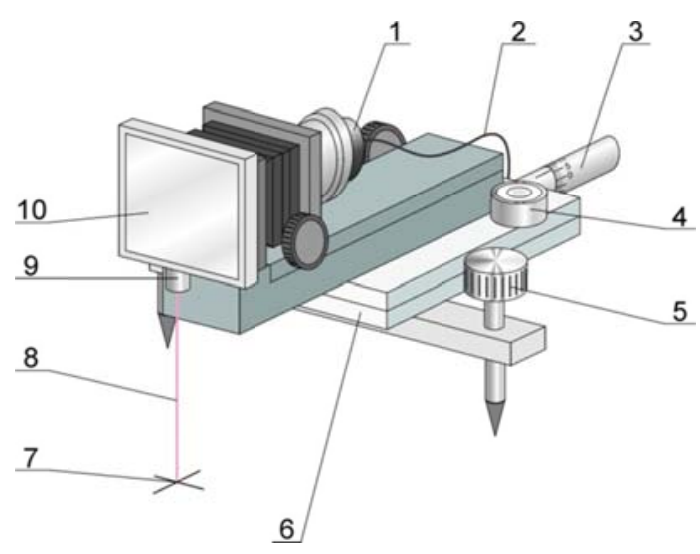

Fig. 2. Project of receiver with a CCD camera and laser plummet.

Symbols: 1 - CCD camera, 2 - communication cable, 3 - micrometer screw of longitudinal motion , 4 - circular level, 5 - adjusting screw, 6 - body, 7 - geodetic point, 8 - the laser plummet, 9 - laser diode, 10 - screen.

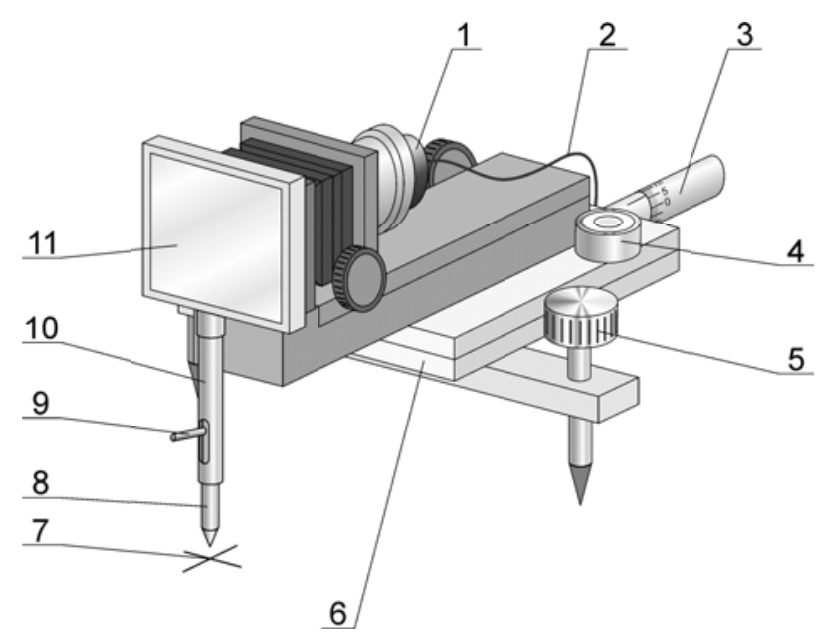

Fig. 3. Project of receiver with a CCD camera and mechanical plummet (center punch). Symbols: 1 - CCD camera, 2 - communication cable, 3 - micrometer screw of longitudinal motion, 4 - circular level, 5 - adjusting screw, 6 - body, 7 - geodetic point, 8 - center punch, 9 - release, 10. - mechanical plummet, 11 - receiver's screen. 
During survey works, which are connected with prolonging and renewing of setting out the rectangular horizontal geodetic control network, the location of the subassemblies of the designed set is presented in figure 4.

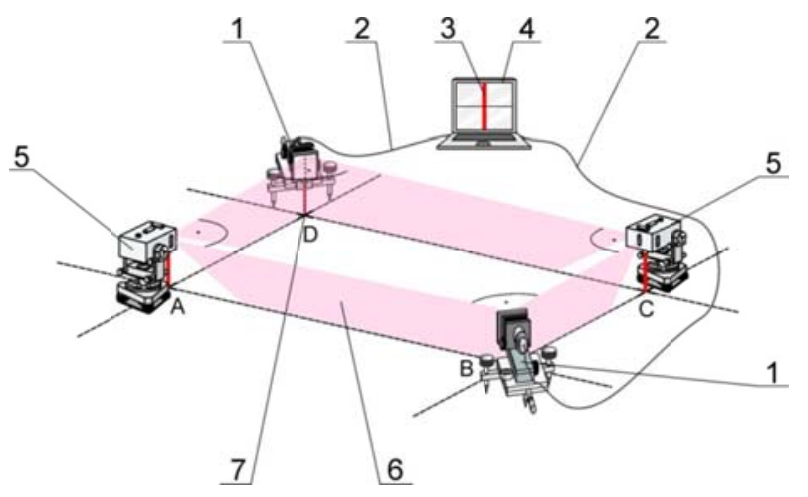

Fig. 4. Example of experimental elements set arrangement on surveying object.

Symbols: 1 - receiver with a CCD camera, 2 - communication cable, 3 - registered images of the laser planes' edges, 4 - computer monitor, 5 - laser transmitter, 6 - vertical laser plane, 7 - geodetic point.

With the mentioned set it is also possible to build different shapes of geodetic control networks as shown in figure 5.
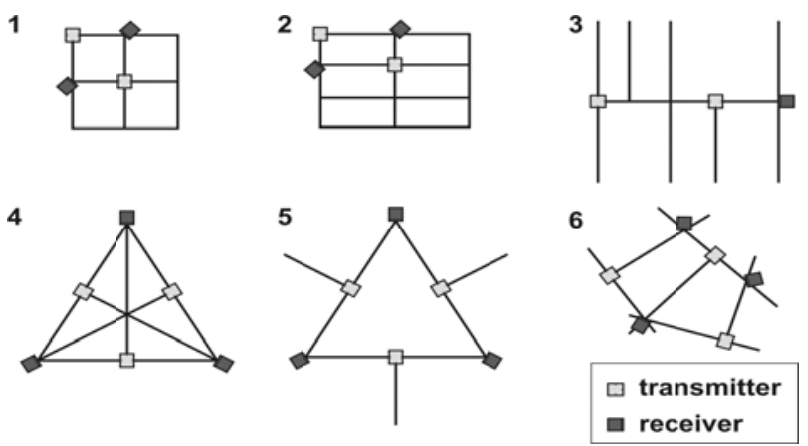

Fig. 5. Examples of geodetic networks designated by measuring equipment set.

In case of necessity for prolonging or renewing of control points that are above the given height over the industrial hall's floor or engineering objects, the set may be positioned on tripods as presented in figure 6.

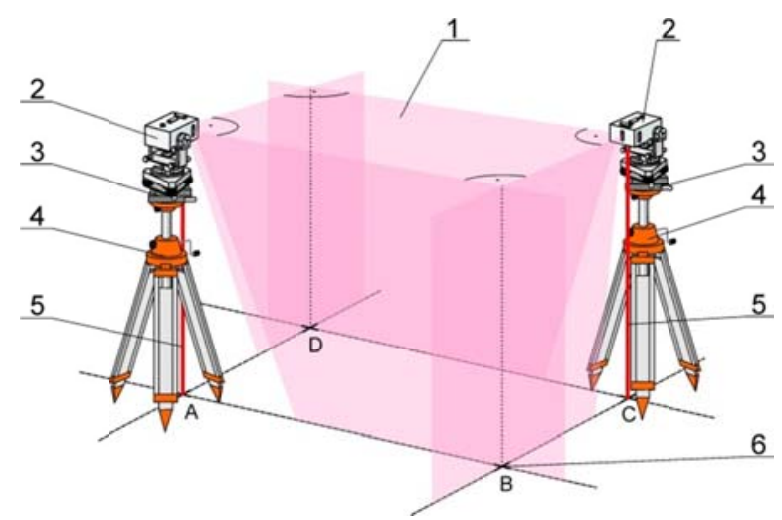

Figure 6. Staking network side with laser transmitters which set on tripods.

Symbols: 1 - vertical laser planes, 2 - transmitter, 3 -tribrach, 4 - tripod, 5 - laser beam, 6 - edge of the intersection of the two vertical laser planes, $A, B, C, D$-geodetic points. 
During setting up of the marking control point's position with the use of the measurement receiver with relation to the established laser planes, which are on the geodetic control networks' sides, observations are made with the portable computer (figures 7A and 7B). On its screen there are visible parts of currently registered lines that are resulted from intersection of the screen surface with the vertical laser planes. At the initial phase there are two parallel lines (figure 7A), which can be brought to the common line with use of the micrometer screw (figure7B). In this position the centering-up device of the receiver is over the marked or renewed control point. Depending on the needs, the mentioned centering-up device may be laser or mechanical plummet. The presented situation is shown in figures 2 and 3 .
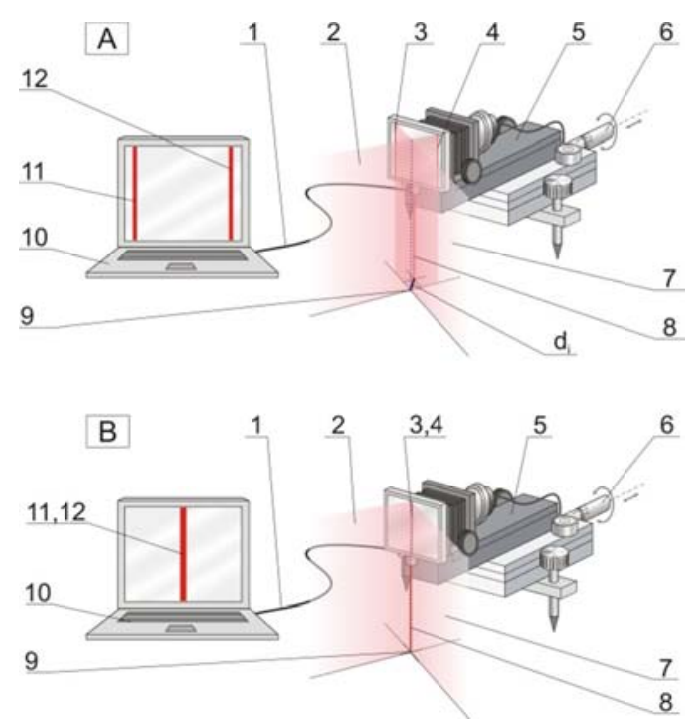

Fig. 7. Method of centering of the measuring receiver over geodetic point: A. initial setting, B. final setting. Symbols: 1 - communication cable, 2 i 7 - vertical laser planes, 3 i 4 - the laser planes' edges on the receiver's screen, 5 - receiver, 6 - micrometer screw, 8 - laser plummet, 9 -geodetic point, 10 - computer, 11 i 12 - registered image of the laser planes' edges, $d_{i}$-horizontal distance between the geodetic point and the current position of the laser plummet beam.

\section{The initial testing of the prototypical set of the laser transmitters and the receiver with CCD/CMOS camera}

On the basis of the design guidelines there have been constructed the set of the mentioned devices, presented as prototypes in figures 1 and 2.

The prototypes have been experimentally tested under laboratory conditions to determine:

1. the measurement repeatability of the set of devices based on the nine registered sequence of the images showing the mutual position of the vertical laser planes' edges;

2. the registration accuracy of the extracts of the registered images of the vertical, assembly laser planes' edges with the use of the micrometric table;

3 . the identification accuracy of the covering of images of the vertical, assembly laser planes' edges in two versions of performing a direct reading (visual) on:

a) the flat receiver's screen

b) the in real time projected image on the monitor's screen. 
The recurrence research of the measurement of the set of devices is conducted on the basis of the registered images in nine different positions of the receiver's screen with relation to the vertical laser planes, emitted by the two laser transmitters (figure 8).

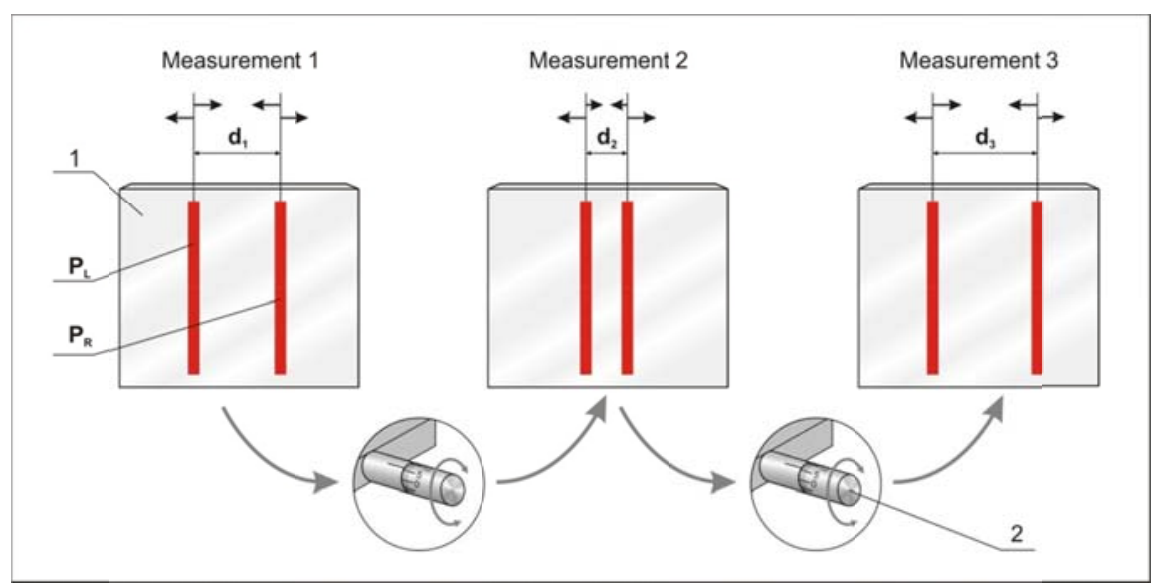

Fig. 8. Idea of measurement repeatability research of devices.

Symbols: 1 - monitor's screen, 2 - micrometric screw of the receiver table, $P_{L}$ - left laser plane, $P_{R}$ - rights laser plane, $d_{i}$ - distance between the laser planes edges' images.

The micrometric screw of the table is used to change the position of the receiver's screen. The determined position of the receiver was read on the scale of screws.

Measurement repeatability has been set up on the basis of 2, 3 or 4 measurement cycles. In each measurement cycle, using the micrometric screw's scale, there has been led to the determined receiver's position, which has been e registered every time a form of the image. Based on the registered images and using the author's program written in the MATLAB software environment, there has been set up the mutual position of the registered planes' edges and then there has been calculated the distances between the planes' edges.

The measurement and computation results are presented in table 1 . The global mean deviation error $m_{0}$ of the measurement repeatability has come to $\pm 0.016 \mathrm{~mm}$ (that is 0.77 pixel).

Figure 9 presents sequential positions of the receiver's screen in relation to the laser planes, emitted by the transmitters.

The first three figures 9A, 9B, 9C illustrate the receiver's positions, at which the screen is before the determined geodetic point. In the figure 9D there have been presented the receiver's position, at which the screen has been located behind the determined geodetic point. In this position on the registered image there has been taken the change of the laser planes' edges, which have been observed on the screen. As a result, the calculated distance between them is negative. 
Table 1. The evaluation of the measurement repeatability of the set of devices on the basis of the registered sequence of images.

\begin{tabular}{|c|c|c|c|c|c|c|}
\hline \multirow[t]{2}{*}{$\begin{array}{l}\text { Positions } \\
\text { of the } \\
\text { receiver's } \\
\text { screen }\end{array}$} & \multirow[t]{2}{*}{$\begin{array}{c}\text { Calculated the } \\
\text { distances } \\
\text { between the } \\
\text { planes' edges }\end{array}$} & \multirow[t]{2}{*}{$\begin{array}{l}\text { Mean } \\
\text { value } \\
\\
\text { [pix] } \\
\end{array}$} & \multirow[t]{2}{*}{$\begin{array}{c}\text { Number of } \\
\text { measurement } \\
\text { cycles } \\
n_{i}\end{array}$} & \multirow[t]{2}{*}{$\begin{array}{c}\text { Residue } \\
\text { from the } \\
\text { mean } \\
\text { value } \\
v_{i} \\
\\
\text { [pix] }\end{array}$} & \multicolumn{2}{|c|}{$\begin{array}{c}\text { The } \\
\text { measurement } \\
\text { mean error in } \\
\text { the fixed } \\
\text { position of the } \\
\text { receiver's } \\
\text { screen } \\
m_{i}\end{array}$} \\
\hline & & & & & [pix] & {$[\mathrm{mm}]$} \\
\hline \multirow{3}{*}{1} & 503.0 & \multirow{3}{*}{503.02} & \multirow{3}{*}{3} & -0.03 & \multirow{3}{*}{0.10} & \multirow{3}{*}{0.002} \\
\hline & 502.9 & & & -0.08 & & \\
\hline & 503.1 & & & 0.11 & & \\
\hline \multirow{3}{*}{2} & 411.5 & \multirow{3}{*}{410.92} & \multirow{3}{*}{3} & 0.62 & \multirow{3}{*}{0.55} & \multirow{3}{*}{0.012} \\
\hline & 410.5 & & & -0.45 & & \\
\hline & 410.8 & & & -0.17 & & \\
\hline \multirow{3}{*}{3} & 317.1 & \multirow{3}{*}{317.06} & \multirow{3}{*}{3} & 0.08 & \multirow{3}{*}{0.68} & \multirow{3}{*}{0.014} \\
\hline & 316.3 & & & -0.72 & & \\
\hline & 317.7 & & & 0.64 & & \\
\hline \multirow{3}{*}{4} & 221.9 & \multirow{3}{*}{221.29} & \multirow{3}{*}{3} & 0.59 & \multirow{3}{*}{0.99} & \multirow{3}{*}{0.021} \\
\hline & 221.8 & & & 0.55 & & \\
\hline & 220.1 & & & -1.15 & & \\
\hline \multirow{3}{*}{5} & 130.5 & \multirow{3}{*}{130.50} & \multirow{3}{*}{3} & 0.00 & \multirow{3}{*}{0.50} & \\
\hline & 130.0 & & & -0.50 & & 0.011 \\
\hline & 131.0 & & & 0.50 & & \\
\hline & -55.0 & & & 0.88 & & \\
\hline 6 & -56.5 & & & -0.63 & & \\
\hline 0 & -55.0 & -55.88 & 4 & 0.88 & 1.03 & 0.022 \\
\hline & -57.0 & & & -1.13 & & \\
\hline & -164.0 & & & -0.92 & & \\
\hline 7 & -163.0 & $163 \Omega 8$ & 3 & 0.08 & 0.88 & 0.018 \\
\hline & -162.3 & 163.08 & & 0.83 & & \\
\hline & -257.4 & & & 0.37 & & \\
\hline & -258.0 & - & & -0.23 & & O 032 \\
\hline 8 & -256.0 & 257.77 & 4 & 1.77 & 1.52 & 0.032 \\
\hline & -259.7 & & & -1.90 & & \\
\hline 0 & -308.2 & - & & 0.31 & & \\
\hline 9 & -308.8 & 308.52 & 2 & -0.31 & 0.45 & 0.009 \\
\hline & The global me & n devia & ion error $\boldsymbol{m}_{0}$ & & 0.77 & 0.016 \\
\hline
\end{tabular}




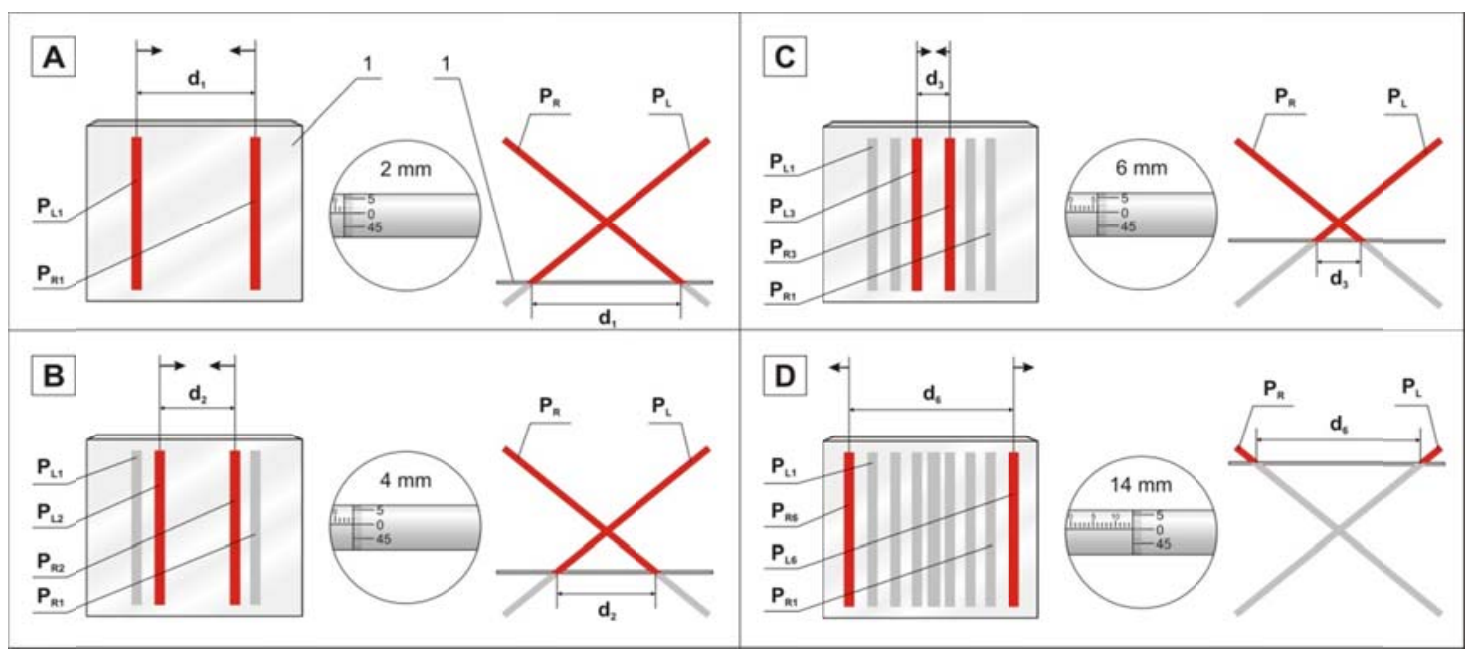

Fig. 9. Positions of the receiver in relation to the laser planes: A., B., C. receiver located before the geodetic point, $D$. receiver located behind the geodetic point.

Symbols: 1 - receiver's screen, $d_{i}$ - distance between the laser planes edges' images, $\mathrm{P}_{\mathrm{L}}-$ left laser plane, $\mathrm{P}_{\mathrm{R}}-$ rights laser plane.

In table 2 there have been presented the reading results of the micrometric screw's scale for the six determined receiver's positions and the corresponding to them average calculated distances between the energetic centres of the planes in relation to the initial position. The last column presents the distance differences between the measurement on the image and the reading on the micrometric screw's scale. These differences are within the range of $-0.032 \mathrm{~m}$ and $0.033 \mathrm{~mm}$. Setting up the distance accuracy, calculated on the basis of the pairs of observations has come to $\pm 0.018 \mathrm{~mm}$, which is 0.8 pixel.

The latest research of the measurement set has concerned the accuracy determination of the covering identification of the vertical laser planes edges' images, bringing them visually to coincidence (figure 10).

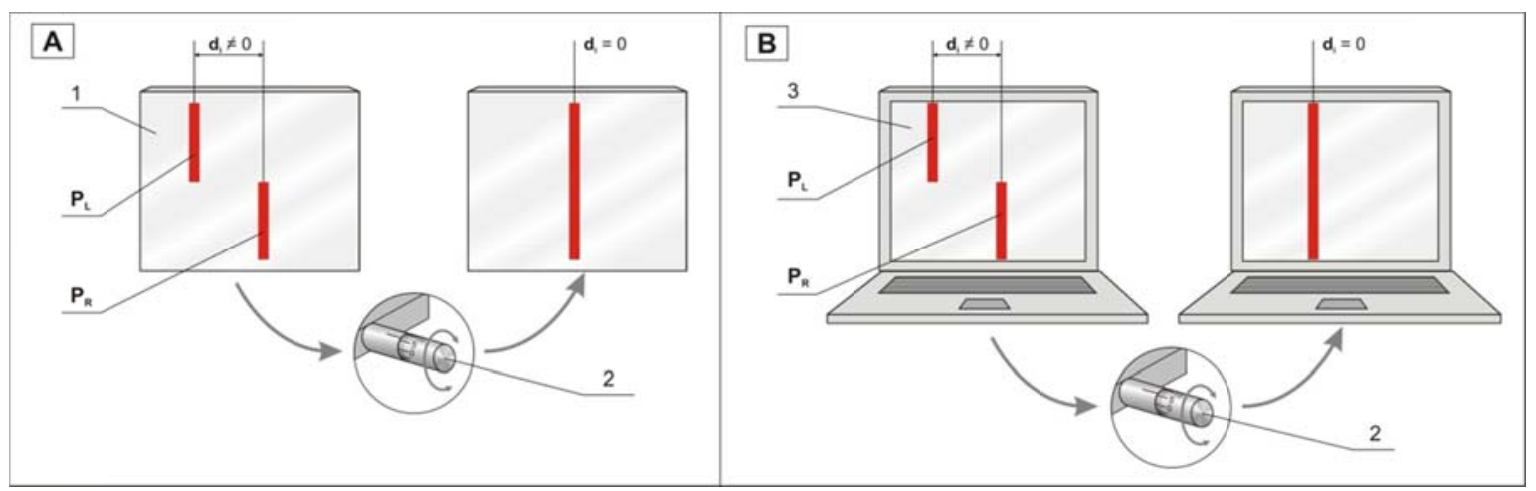

Fig. 10. Illustration of visual coincident of vertical edges laser planes: direct reading on the flat receiver's screen, B. direct reading of the projected in real time image on the monitor's screen. Symbols: 1 - receiver's screen, 2 - micrometric screw of the receiver table, 3 monitor's screen, $d_{i}$ - distance between the laser planes edges' images, $\mathrm{P}_{\mathrm{L}}$ - left laser plane, $\mathrm{P}_{\mathrm{R}}$ - rights laser plane 
Table 2. The accuracy evaluation of the distance calculation between the energetic centres of the vertical laser planes' edges with the use of the micrometric table

\begin{tabular}{|c|c|c|c|c|c|c|}
\hline \multirow{2}{*}{ 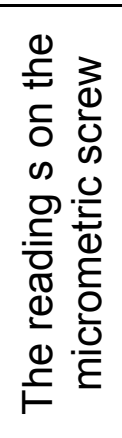 } & \multicolumn{3}{|c|}{$\begin{array}{l}\text { The calculated distance } \\
\text { between energetic centres of } \\
\text { the laser planes on the } \\
\text { registered images }\end{array}$} & \multirow{2}{*}{\multicolumn{2}{|c|}{$\begin{array}{l}\text { The calculated } \\
\text { difference } \\
\text { between energetic } \\
\text { centres of the } \\
\text { planes in } \\
\text { reference to the } \\
\text { initial position (on } \\
\text { the registered } \\
\text { images) }\end{array}$}} & \multirow{2}{*}{$\begin{array}{l}\text { The direction } \\
\text { difference } \\
\text { calculated on the } \\
\text { basis of the } \\
\text { measurement on } \\
\text { the image and the } \\
\text { reading on } \\
\text { micrometric } \\
\text { screw's scale }\end{array}$} \\
\hline & $\begin{array}{l}\text { Measure } \\
\text { ment } \\
\text { result }\end{array}$ & $\begin{array}{l}\text { Mean } \\
\text { value }\end{array}$ & $\begin{array}{c}\text { Mean } \\
\text { error of a } \\
\text { single } \\
\text { measurem } \\
\text { ent }\end{array}$ & & & \\
\hline$d_{k}$ & $x_{i}$ & $X_{S}^{\prime} r i$ & $m_{\dot{s} r}$ & $\left.d_{i}=\right)$ & $r_{1}-X_{s} r i$ & $d=d_{i}-d_{k}$ \\
\hline$[\mathrm{mm}]$ & [pix] & [pix] & [pix] & [pix] & {$[\mathrm{mm}]$} & $\begin{array}{c}{[\mathrm{mm}]} \\
([\mathrm{pix}])\end{array}$ \\
\hline 2.00 & $\begin{array}{l}503.0 \\
502.9 \\
503.1 \\
\end{array}$ & 503.02 & 0.10 & 0.00 & 2.000 & $\begin{array}{c}0.000 \\
(0.00)\end{array}$ \\
\hline 4.00 & $\begin{array}{l}411.5 \\
410.5 \\
410.8 \\
\end{array}$ & 410.92 & 0.55 & 92.10 & 3.972 & $\begin{array}{c}-0.028 \\
(-1.33)\end{array}$ \\
\hline 6.00 & $\begin{array}{l}317.1 \\
316.3 \\
317.7 \\
\end{array}$ & 317.06 & 0.68 & 185.96 & 5.982 & $\begin{array}{c}-0.018 \\
(-0.86)\end{array}$ \\
\hline 8.00 & $\begin{array}{l}221.9 \\
221.8 \\
220.1 \\
\end{array}$ & 221.29 & 0.99 & 281.73 & 8.033 & $\begin{array}{c}0.033 \\
(1.56)\end{array}$ \\
\hline 10.00 & $\begin{array}{l}130.5 \\
130.0 \\
131.0 \\
\end{array}$ & 130.50 & 0.50 & 372.52 & 9.977 & $\begin{array}{c}-0.023 \\
(-1.10)\end{array}$ \\
\hline 14.00 & $\begin{array}{l}-55.0 \\
-56.5 \\
-55.0 \\
-57.0\end{array}$ & -55.88 & 1.03 & 558.89 & 13.968 & $\begin{array}{l}-0.032 \\
(-1.54)\end{array}$ \\
\hline & & & Measure & ent ac & racy & $\begin{array}{c}0.018 \\
(0.84)\end{array}$ \\
\hline
\end{tabular}

Each of the vertical laser planes has been represented by the section, which has been registered as segment visible on the top or bottom of the image.

Such a representation of the vertical laser planes' edges at their identical colour has enabled to get more accurate coincidence and proper identification during working up the registered images.

The experimental studies have been conducted in both of the illustrated versions:

- at the direct reading (with the naked eye) on the flat receiver's screen (figure 10A);

- at the direct reading (visual) of the in real time projected image on the monitor's screen (figure 10B). 
In table 3 there have been presented the readings' results of the micrometric screw's scale for such a position of the receiver, that has been resulted from a coincidence of the extracts of the vertical laser planes' edges. The coincidence of the laser planes has been carried out in two versions. At the direct reading (with the naked eye) on the receiver's screen there have been conducted 4 measurements. In the second version at the direct reading (visual), for the in real time projected image on the monitor's screen, there have been conducted 5 images' registrations. Based on the calculations carried out for each version there have been calculated the mean value of the readings on micrometric screw's scale and its error. After that there have been calculated the distances on the image between the laser planes' edges, their mean values and the errors.

Table 3. The evaluation of the covering accuracy of the laser planes edges' images

\begin{tabular}{|c|c|c|c|c|c|c|c|}
\hline \multirow[t]{2}{*}{$\begin{array}{c}\text { Visual } \\
\text { coincidence } \\
\text { of the } \\
\text { planes'edges }\end{array}$} & \multirow[t]{2}{*}{$\begin{array}{c}\text { Readings } \\
\text { on the } \\
\text { micrometric } \\
\text { screw's } \\
\text { scale } \\
\end{array}$} & $\begin{array}{l}\text { Mean } \\
\text { value }\end{array}$ & $\begin{array}{c}\text { Mean } \\
\text { value's } \\
\text { error }\end{array}$ & \multicolumn{2}{|c|}{$\begin{array}{l}\text { Distance on } \\
\text { the image } \\
\text { between the } \\
\text { laser planes } \\
\text { edges' images }\end{array}$} & \multirow{2}{*}{$\begin{array}{c}\text { Mean } \\
\text { value } \\
{[\text { pix }]} \\
([\mathrm{mm}])\end{array}$} & \multirow{2}{*}{$\begin{array}{c}\text { Mean } \\
\text { value's } \\
\text { error } \\
{[\mathrm{pix}]} \\
([\mathrm{mm}])\end{array}$} \\
\hline & & \multicolumn{2}{|l|}{ [mm] } & [pix] & {$[\mathrm{mm}]$} & & \\
\hline \multirow{4}{*}{$\begin{array}{l}\text { on the } \\
\text { receiver's } \\
\text { screen }\end{array}$} & 14.00 & \multirow{4}{*}{14.065} & \multirow{4}{*}{0.048} & 7.4 & 0.159 & \multirow{4}{*}{$\begin{array}{c}6.1 \\
(0.130)\end{array}$} & \multirow{4}{*}{$\begin{array}{c}0.8 \\
(0.018)\end{array}$} \\
\hline & 14.06 & & & 7.5 & 0.161 & & \\
\hline & 14.09 & & & 5.4 & 0.116 & & \\
\hline & 14.11 & & & 4.0 & 0.086 & & \\
\hline \multirow{5}{*}{$\begin{array}{l}\text { on the } \\
\text { monitor's } \\
\text { screen }\end{array}$} & 14.12 & \multirow{5}{*}{14.160} & \multirow{5}{*}{0.029} & 0.0 & 0.000 & \multirow{5}{*}{$\begin{array}{c}-1.0 \\
(-0.021)\end{array}$} & \multirow{5}{*}{$\begin{array}{c}1.4 \\
(0.030)\end{array}$} \\
\hline & 14.15 & & & 2.6 & 0.056 & & \\
\hline & 14.16 & & & -4.4 & -0.094 & & \\
\hline & 14.17 & & & -3.0 & -0.064 & & \\
\hline & 14.20 & & & 0.0 & 0.000 & & \\
\hline
\end{tabular}

On the basis of the results presented in table 3 there can be noticed that in case of the visual coincidence on the camera's screen there has occurred a systematic error of the value of approximately 6 pixels.

The reason for this error's occurrence has been a differential laser light's intensity, which has been emitted by the receivers, and the size of the camera's screen (image scale 1:1).

In the second version, in which there has been conducted the planes' edges coincidence on the screen (image scale 3:1), a systematic error can be omitted.

\section{Conclusions}

The set of measurement devices, presented in the article, has an innovative character. Concerning authors' intention, this is the set supporting geodetic surveys such as prolonging and renewing of setting out horizontal control points.

The common accessibility and at the same time the low cost purchase of the optoelectronic subassemblies, which compose the measurement set, unable to an extensive use of the set in field survey works. 
The technical parameters of the CCD/CMOS cameras and the solid-state lasers unable a miniaturization and a portability as well as ensure a long-lasting exploitation, resulting from the use of supply sources, which are safe for living organism.

The authors worked out and created the set of measurement devices in two versions, that unable a prolonging or renewing of control points on the level of the industrial hall's floor (figure 2 and figure 3 ). It is also possible to position the set on tripods over the industrial hall's floor (figure 6).

With the use of the created set of devices there can be done a prolonging of points of differential geometric shaped geodetic control networks.

It is necessary then to have enough laser transmitters and receivers.

One person is enough to do geodetic surveys with the use of the measurement set.

The prototypical set has been experimentally tested under laboratory conditions. Based on the study and analysis of accuracy, following conclusions were reached:

1. The identification repeatability of the laser planes, that has been received by the CMOS camera, located on the micrometric table, has come to $\pm 0.016 \mathrm{~mm}(0.8$ pixels);

2. The measurement accuracy of the set of devices, resulting from identification of the energetic centres of the laser planes' edges, visualizing the geodetic control networks' sides, for short distances between $2.0 \mathrm{~m}$ and $20 \mathrm{~m}$, has varied between $\pm 0.02 \mathrm{~mm}$ and $\pm 0.05 \mathrm{~mm}$;

3. The visual identification accuracy of the covering of images of the vertical laser planes' edges, independently from the way of bringing them to a coincidence, has come to $0.02 \mathrm{~mm}$. In case of using the camera screen there has occurred a systematic error amounts to $0.13 \mathrm{~mm}$;

4. The accuracy of a stabilization or renewing of the setting out a horizontal control point, using the CMOS camera, has come to about $\pm 0.25 \mathrm{~mm}$;

5. The accuracy of a stabilization or renewing of the setting out a horizontal control point, at positioning the laser edges with the naked eye on the screen surface of the receiver's camera, has come to about $\pm 0.35 \mathrm{~mm}$.

\section{References}

Ágfalvi, M., Bokor, Zs., Farkas, R., Gyenes, R., Tarsoly, P., (2006). Geodetic Control and Setting Measurements in Mechanical Metrology XXIII FIG Congress (Munich: Germany) pp 1/11-10/11

Batusov, V., Budagov, J., Khubua, J., Lasseur, C., Lyablin, M., Russakovich, N., Sissakian, A. and Topilin, N., (2009). Laser Beam Fiducial Line Application for Metrological Purposes Physics of Particles and Nuclei, Vol. 40, No. 1, pp 115-129

Ćmielewski, K., (2007). Fibre optics and laser technology in high precision measurements of shapes and deformations of engineering objects ZN UP we Wrocławiu Nr 551 Rozprawy CCXLVI Wrocław p 242 (in Polish)

Herty, A. and Albert, J., (2002). High Precision Survey and Alignment of Large Linear Colliders - Horizontal Alignment Proceedings of the 7th International Workshop on Accelerator Alignment, SPring-8 (Japan) pp 413-424 
Kavanagh, B. F., (2010). Surveying with construction applications - 7th ed. (New Jersey: Prentice Hall) p 685

Kuchmister, J., Ćmielewski, K., Gołuch, P., Kowalski, K., (2012). Application of the laser plummet to measure the linearity of elongated objects Acta Sci. Pol. Geod. Descr. Terr. 11 (1) 5-16 (in Polish)

Leica T-Probe, T-Scan (2012). Datasheets Hexagon AB (Unterentfelden: Switzerland)

Matsui, S. and Zhang, C., (2002). Alignment method for 50m distance using laser and CCD camera Proceedings of the 7th International Workshop on Accelerator Alignment, SPring-8 (Japan) pp 127-139

Mora, A. S., (1998). Aplicaciones industriales de la topografía. (Madrid-CastillaLa Mancha: Colegio Oficial de Ingenieros Técnicos en Topografía) p 367 (in Spain)

Pelzer, H., (1988). Ingenieurvermessung - Deformations-messungen Massenberechnung. Ergebnisse des Arbeitskreises 6 des Deutschen Vereins für Vermessungswesen (DVW) e.V. (Stuttgart: Verlag Konrad Witwer) (in German)

Schofield, W. and Breach, M., (2007). Engineering surveying - 6th ed. (Oxford, UK: Elsevier Ltd.) p 622

Schweitzer, J., Kochkine, V., Schwieger, V. and Berner, F., (2012). Quality assurance in building construction, based on engineering geodesy processes FIG Working Week (Rome: Italy)

\section{Authors:}

Kazimierz Ćmielewski ${ }^{1)}$, kazimierz.cmielewski@igig.up.wroc.pl Janusz Kuchmister ${ }^{1)}$

Piotr Gołuch ${ }^{1)}$

Izabela Wilczyńska ${ }^{1)}$

Krzysztof Kowalski ${ }^{2)}$

1) Institute of Geodesy and Geoinformatics,

Wroclaw University of Environmental and Life Sciences,

Grunwaldzka 53, 50-357 Wroclaw, Poland

2) Regional Water Management Board in Wroclaw, Norwida 34, 50-950 Wrocław, Poland 